Volume 1 No. 1, Agustus 2018

E-ISSN 2622-9056

Universitas Banten Jaya

\title{
JARGONITIS AS SEEN ON “AQUA” BOTTLE
}

\author{
HENDRA \\ Banten Jaya University \\ Serang, Indonesia \\ hendra_cs@yahoo.com/kemahasiswaan.unbaja@gmail.com
}

\begin{abstract}
This research is aimed to describe the jargonitis created by PT Danone as the company producing "Aqua." Then, the analysis was based on the cohesion and coherences provided on the label of "Aqua." The jargonitis was created by the company to attract the market target, in this case the teenagers as the largest consumers in the world. In a business world, there are some efforts conducted by a company for the products released can be effective for some people, inthis case, to attract some people. The effective method to conduct the efforts is by marketing. One of the methods done by a mineral water company is by creating jargonitis. Therefore, some people will remember the jargon with the purpose of the company that "someone could not focus if the were dehydrated." The study used content analysisi method. As the results of the research are the meaning of Jargontitis that it can be divided into three parts; 1) Onomatopoeic based Jargon; 2) Blend and Acronym based Jargon; and 3)Pidgin Based Jargon. Therefore, some teenagers will use the jargons in their activities and indirectly they will remember "Aqua" as the focus maker.
\end{abstract}

Keywords: Jargonitis, “Aqua” Bottle

\section{INTRODUCTION}

Marketing is one of the methods for a company to gain some customers or consuments. Event, in marketing, some companies will do some researches to make the products produced effectively to gain some customers or consuments. The candidates of customers can be called as "market target" (Larsen, 2014: 1). The target market should be chosen or decided firstly before conducting the market research. Market target also will give the perception about the products before the market analyst conducts the market research.
Then, the result will be received in the form of marketing strategy (Larsen, 2014: 1).

Marketing strategy is the result of market research conducted by a company. The market research done by a company to see whether the old or new product can be effective. The market research should be done because there are some competitors that release the similar product. There are so many market strategies done by a company to make the products become effective in society and it is done to anticipate the competitions. The point of marketing strategy is to gain the objective of the company (Schlais, 2011: 76). 
There are so many marketing strategies done by a company. One of the effective marketing strategy is advertising. However, the cost for the advertisement is so expensive; it is more if it is shown on television. In Indonesia or in other countries, the cost of avertisement will be based on duration and frequency (Sclais, 2011: 44). However, "Aqua" a product produced by "Danone", will make the marketing strategy by making some jargons popular. For popularizing the jargons, "Aqua" just made two advertisements; the advertisement that caontains of the jargon of "Zonk" and the advertisement that contains of the jargon of "Sekip." Then, in the end of the advertisement, there will be a question "Is there “Aqua"?"However, before the sequential advertisements of jargon, there existed an "introduction" advertisement that there were two people that has failed in their focus so that they need "Aqua." Since the advertisement, there is a trend among teenagers' interactions, that is a trend for saying "gagal fokus" (Focus Failure).

Most ofthe jargonitis are on the label of the medium size of "Aqua" bottle. Based on the explanation, it is seen that "Aqua" company (Danone) wants to have an efficiency in the cost of "Aqua" in the cost of advertisement.
Therefore, based on the existed jargons, the teenagers want to know more about the jargons that they may use. And, the jargons are o the medium size of "Aqua" $(600 \mathrm{ml})$.

Therefore, there are so many market strategies based on the market analysis, one of the examples is why some companies moved to some developing countris to apply the cheaper products with the high quality. Then, some companies also make some teenagers as the market targets as teenagers are as the largest customers or consumers in the world (Akcay, 2012: 10). One of the companies that has made the teenagers as the market target is "Danone" that produces Mineral Water "Aqua."

"Aqua" is the first mineral water produced in Indonesia before the others follow "Aqua." Event, "Aqua" has created "brand image" or some people will know the brand than the name of mineral water itself (Akcay, 2012: 12). One of the examples, someone who will say "buy me Aqua!" but the person asked will buy the mineral water in different brand. That is the example of "Brand Image." The company even has created some Marketing strategies followed by the other mineral water company such as the size of mineral water's bottles; large, medium, and small. 
The other marketing strategies done by "Aqua" is by using television as the media to promote the products. In this case, the company has used the advertisements by showing the production of "Aqua" (Pure from filtered mountain water). Nowadys, the minera water (Aqua) has made two kinds of advertisement; for general that will show the producing of "Aqua" and the advertisements for teenagers that show the errors made by the teenagers as the result of dehydration that will create "focuse failure. Teenagers can be as the market target because they are energic and they always do some activities whether they are indoor or outdoor (Akcay, 2012: 10).

Besides, teenagers or youths always make some language variation when they interact with themselves. They They make the language variation as a trend (Mahdad, 2012: 61); if they do not use some language variation, they will considered as the old fashioned ones. Language variation used by some teenagers will be in the form of words or vocabularies because they are easily formed by the teenagers (Mahdad, 2012: 28). Besides vocabularies, teenagers also like to change the syntactic structure for making it easier for them to make some interactions (Martinez, 2011:107).
Therefore, some terms will be updated by teenagers from time to time to show that they are not old fashioned. Then, "Aqua" used the situation as the market strategy that can attract some teenagers. In this case, "Aqua" will create some jargons (jargonitis) for the teenagers can remember and use it in daily activities.Using jargons is one of the strategies while making an interactions and it will impact the others (Patoko and Yasdanofard, 2014:569). The jargons are the terms if the teenagers will lose focus and do error activities. It happened if the bodies are dehydrated. Even, in the television advertisements of "Aqua", there is a question, "is there "Aqua?" that it also shows the effective marketing strategy. Thus, the question is always heard in daily life.

The jargons are existed in the medium bottle of "Aqua" and it is not on the large and small size bottle of "Aqua." The large size is consumed by family that contains of a few people. Then, it is seldom for some older people use the updated terms to the children. The small size does not use the jargon also because the small size is just bought by the people that want to lose the thirsty with enough money. However, the medium size is the bottle bought by some people more, especially 
teenagers. It is caused by the activities of the teenagers.

In some activities, there are some words that finally can be jargons or trends in an ineraction of some people. The term of jargonitis relates to jargon creating or paradigm, heuristic, trace, and even hybrid (Sword, 2012: 51). Then, what will be discussed is the discussion abiut jargon itself. Jargonitis is related to the vocabularies or some terms that are used to attract some readers. Besides, words or the terms are the style of the writer him or herself. Even, with the existence of jargon, many people want to popularize the jargon. However, the term of Jargon itself is the special terms to such fields that can be remembered by some people. Jargon signs the technical terms or idioms that have some characteristics from social activities (Sword, 2012: 119). Thus, it can be said that in social activities, such society will use such jargons.

In sociolinguistics, Jargons also can considered as pidgina because they were used by such social communities. Thus, jargons can be said as the words or a language that do not belong to the community but they were taken by such community(Sword, 2012: 51). As an example of jargon that is actually a pidgin is the word "corn" in civil engineering that is actually the mixture of cement, sand, etc. However, because of the difficulty of pronunciation, in Bahasa, it has chnged to become "coran."

Therefore, the point of the jargon focuses on the change on sound. Even, there are some jargons that can be a vocabulary in such languages. In this research, the jargons taken mostly sourced from the sound arranged so that it can be remembered by teenagers as the target of "Aqua." Some examples of Jargonitis that can attract some teenagers are the sounds, such as "Krik- Krik", "Gubrak", etc. Then, the pidgins that can be the jargons are "Zong", "Bingo", etc.

The main focus is the jargonitis as a marketing strategy as seen on "Aqua" bottle. Then, it will describe the phonolical based Jargon and the contraction based jargon. Linguistically, Jargonitis is the method to influence teenagers for making it to become a trend. Then, theoretically, it will contribute to the field of linguistics, in this case discourse analysis and to the other field, in this case, to the field of economy, especially to the field of marketing. In marketing strategy, teenagers are also the target as they are the largest consumers in the world. 
Besides, the result of the analysis can be applied to some companies that teenagers are the effective market target also. Then, teenagers are part of society that always use language varition as a trend. Thus, for attracting teenagers, a company also can create new trend. Thus, besides developing the trend, teenagers can focus on the product of the company.

The approaches used in analysing the meaning of jargonitis will be based on the cohesion and coherence as the important approaches in Discourse analysis. There are some clues that can be used to determine the meaning of a sentence or even a word. The meaning of a word can be interpreted based on the structure. In this case, grammar is so important to interpret a sentence or "surface text" (Beaugrande, 1981: 3)The technique of interpreting based on the meaning of a sentence or grammatical form can be said as the cohesion. Some people know the interpretation based on the cohesion is about syntax. However, the other aspect of grammar is also about lexical aspect or morphology besides syntax (Murpgy and Koskela, 2010: 3)Without lexical or morphology, a meaning is hard to understand. Although it is in the form of jargon, there is a meaning of the jargon that will be analyzed. Besides, There is a situation when the jargon is used.

Even, the structure from the smaller to the higher ones can impact the meaning of a sentence. Basic phrase or a clause in English can be considered as the relationship of some elements (Beaugrande, 1981:50). Even, some words will be chosen as Node so that the meaning will be fit based on the purpose (Beaugrande, 1981: 50). The combination will make the meaning of a sentence. For making a meaning of a sentence, sometimes the text maker will repeat the desired words. The repetition for strengthening can be called as Recurrence.

In jargonitis existed in Aqua, there are some jargons that has been repeated. It is done for strengthening the meaning. Even, related to the jargon, there are the way of pronuncing and the meaning as like as a dictionary. There are some repetitions made like "Incar rendang yang digigit lengkuas, kamu "KZL" (You want to eat rendang, but what You eat is lengkuas. You are "KZL." And there is the process of reccurence below the term, that is $\mathrm{KZL}=$ Kesel. Then, the repetition is on the other side of the label that is considered as the lexicon (the meaning based on dictinary), that is"[ke.ze;] Letupan emosi yang disebabkan oleh 
mentoknya kesabaran dan gagal fokus." ([ke.ze;] Kind of emotion that is caused by loosing patience and focus failure.")Thus, it is seen that the recurrence can be interpreted as the strengthening the meaning of the jargonitis made.

Coherence is the conrast of cohesion that will see the meaning based on the grammatical structure. However, will interpret a text based on the meaning. In this case, the meaning will be viewed syntactically (Baker and Ellece, 1988: 16). Therefore, it will analyse the maning based of semantic too. Then, it also analyses the implicature on a text. Sometimes, the meaning of a text will have a different meaning from what it looks like. Besides, the meaning of a text will be supported by the events and situations occured in a text. In other words, the existence of events and situations will activate the operations that will create coherence relations (Antia, 2000: 66). Related to the statement, there are two kinds of coherence patterns. The first will explain as a mental store of abstract coherence expectancies or relations such as agent, attribute, part, instrument, cause, motions, etc. Then, for getting the meaning, there must be an intertextual mediation needed (Antia, 2000: 66). As an example from the analysis that the researcher wants to analyze is the word "Distrek" on the label of Aqua. It is hard to understand because there is a sentence on the label that says, "Mau kenalan, Halte kelewatan, kamu "Distrek" (Want to introduce your self to a girl, you pass the bus stop, you are "distrek.'). The word "distrek" is an unfamiliar word that was created by "Aqua" as the jargon. However, there are two clues on the label; the first label on the bottom of the label and the other clue is on the other side of the label. Therefore, the meaning will be explained if there is an intertextual or explaining the meaning. Then, the second kind of coherence pattern is mental storage of specifically interpreted relation associated with a given concept. Therefore, the meaning of a text will be explained with the specific clue. It means although the textcan be understood but it is hard to understand. Thus, the meaning will be exppained by the existence of a given concept. As an example, the word "Garing" in the label of "Aqua" is understandable. However, in the text, it is hard to understand the meaning. It is in the text, "Mencoba melucu lalu dihadiahi tatapan semu membisu, kamu "Garing"”, (Try to make a joke, but you are awarded by the look of confusing, you are "garing"). Then, if the word "Garing" is related to the sentence itself, it is hard to understand, but there is a 
context of situation that will explain the meaning of the word.

\section{METHOD}

The method used in analyzing the jargonitis is content analysis method. The method of content analysis will analyze the content and the meaning existed in the jargon used on the label of "Aqua" (Krippendirf, 2004: 25). Then, the researcher will see or analyse the content contained on the label annd the researcher does not use a claculation statistically. Thus, the writer will use qualitative approach (Kothari, 2004: 5, Cresswell, 2003: 14). Therefore, in analyzing the jargonitis existed on the label of "Aqua." Therefore, in analyzing jargonitis existed on the label "Aqua," there are some jargonitis on the medium size of "Aqua" that will be observed and analyzed and how are the contents of jargonitis on the label of "Aqua." Then, the researcher will observe the impact of jargonitis by interviewing the teenagers in University of Banten Jaya as the sample.

Based on the analysis the writer has conducted, the writer finds that the jargonitis created by "Aqua" as the marketing strategy to market the product classified into three categories. All the categories were analyzed based on the form, the pattern, pronunciation and the sound of the jargonitis created by "Aqua." All the categories will be based on:1) Onomotopoeic based Jargon; 2) Blend and Acronym based Jargon; and 3)Pidgin Based Jargon; Symbol Based Jarrgon.Then, the researcher will analyse the effectivity of the jargon to the teenagers as the market targets.

The Meaning of Jargonitis as seen on the bottle of "Aqua" in a Medium Size

\section{Onomatopoeic Based Jargon}

Onomatopoeia is also included into linguistics. It represents about the sound of a thing or animals produce (Malmkjær, 1995: 14). Onomatopoeic Jargon is the jargon that will be based on the sound of a word. Although onomatopoeic is different but here, the onomatopoeis will be based on Bahasa Indonesia standard (McCarthy, 2002:6). Onomatopoeic is also a word that the meaning can be predicted (Predictable meaning). There are some examples of Onomatopoeic that the meaning can be predicted what it is; such as "miaw" that can be predicted as the sound of a cat. However, it will be different in Bahasa (although some people still can predict the meaning), it is “meong” in Bahasa Indonesia. 
The analysis was based on the classification that the researcher has made to the jargons on the label of "Aqua." The first onomatopoeic jargon the researcher found is word "Gubrak." Similar to the other jargonitis, there are three existences of jargonitis; the main existence is in the top lable of "Aqua" containing of a sentence or situation; below, there will be the meaning of the jargon; then on the other side, there will be a lexicon of a jargon.

\section{"Gubrak"}

The word "gubrak" is the sound of something that is falling down. It could be the sound of a person that falls down or others. In the label of "Aqua", the word is presented in a sentence, "Lari? Lari dari kenyataan? Gubrak!” (Run? Run away from reality? Gubrak). Then, the meaning of the sentence is "run away from reality." Sometimes, the teenagers are still confused with his or her own identity. Even, some teenagers are still hard to manage the problems they face. Therefore, the meaning of the word will be based on the cohesion and coherence. The meaning based on the cohesion is based on the grammatical side; such as lexical meaning and others. In lexical meaning, the word is included to the word that is predictable meaning. It means people can guess what the meaning of "gubrak" is. In analyzing the meaning based on coherence, the researcher will analyze the lexical meaning. Below the statement, there is a meaning of "Gubrak." Although it is the sound of something that falls down, but the meaning is not about the sound. In the meaning, the producer creates the direct meaning by using the symbol of "equals" (=); Gubrak= jatuh perlahan (Gubrak= slowly falls down). Although the maning is not like what it looks like, but the leaxical meaning will be presented in the other side of the label. The other said of label presents "[Gu.brak] hilangnya fokus menghasilkan komen nggak banget, bikin pendengarnya berjatuhan" ( [Gu.brak] the focus failure resulting the undesired comments, makes the hearer falls down).

Therefore, there are two kinds of meaning of "Gubrak" lexically. At first the meaning of "Gubrak" is the real meaning of Gubrak; slowly falls down (below the statement). Then, the second meaning is the situation of Gubrak.Therefore, the meaning of Gubrak lexically (based on the dictionary of "Aqua") is slowly falling down. However, actually the word "Gubrak" is an onomatopoeic; it is the sound of something that is fell down. Altough it is contrast to the 
onomatopoeic meaning, the meaning of gubrak here is the siatuation of someone that falls down. Then, the meaning of "gubrak" based on the situation can be seen on the other side of the label; it is arranged as if it is the meaning of a dictionary (therefore, it can be clled as lexicon); there is the way of pronuncing it and the situation of the meaning. There, there is a way of pronuncing it "[Gu.brak] hilangnya fokus menghasilkan komen nggak banget, bikin pendengarnya berjatuhan" ( [Gu.brak] the focus failure resulting the undesired comments, makes the hearer falls down). There, it can be shown that there are two syllables of "Gubrak." The first syllable is "gu" and then the secnd one is "brak." The pronunciation seems that the producer wants to teach the reader the way of pronuncing it. Then, there is an explanation of "Gurak" that is about undesired comments that has made the hearer falling down. Falling down here is not the real falling down but it shows how the reader is dissapointed after the situation of focus failure.

Then, the meaning based on coherence will be analysed based on the statement in the main label of "Aqua." In the main label of "Aqua", there is a statement "Lari... lari dari kenyataan? Gubrak" (Run, do you run away from reality? Gubrak."'The statement tries to give such a description to the reader about the focus failure happened. Actually, it is the phenomena that always happens to some teenagers. Some teenagers always think that they have some problems. The statement is also based on some problems faced by the teenagers. Since the meaning will be based on the problems faced by the teenagers, the researcher will also relates the condition to the characteristics of teenagers. As the teenagers are still confused for their own existence, they think they have some problems that are hard to solve. It happens because they are lack of experiences (Queensland Government, 2013: 1). Therefore, sometimes the teenagers think the problems are hard to solve and they need to run away. This is what the statement says. However, some people that understand the problem think it is over, so they think they have to "gubrak." Therefore, the meaning of the statement itself means the teenagers should not do the overeaction if they have the problem as the other people think that the problem is usual.

Then, the meaning of "Gubrak" based on cohesion and coherence is about the people that think the problem that some teenagers is so over and it is not a real hard problem. Therefore, some people think that it is usual for 
them, especially the people that have some experiences.

\section{Krik Krik}

The second onomatopoeic based jargon is "Krik Krik." "Krik- Krik" itself is the sound of Cricket.Based on grammar, in this case, based on the cohesion, the statement or the sentence is "Selesai cerita, penonton kecewa, lampu mati... hening... KRIK KRIK." (After telling a story, the audiences are dissapppointed, the light is off... silence... KRIK KRIK). "After telling a story" refers to the teenagers that like to tell a story. A story is the content about something that a teenager likes to tell. The point of a story is giving an information for entertaining the audience. It also means to make the audience feel happy or even funny. Then, it will have an effect to the audience. Then, it is continued to the second sentence, "penonton kecewa" (The audiences are dissappointed). It will show the effect or the influence of the story telling. The story telling does not impact the audience at all. There is no expressions of staisfied from the audiences. "Then, the light is off" means that it will add the expresion of no satisfaction from the audience. Then, it will show the situation like in a village; silence. Then, the meaning is tronger after seeing the meaning on the bottom of the label, the meaning is unknown for "Krik Krik" (Krik Krik= ...). The blanks can mean unknown or even it also can mean silence. However, seeing the condition it could be the condition of silence.The researcher sees the other side of the label (that it can be like the dictionary), there is a lexicon [krik.krik]Klimaks yang terlupakan yang berujunng sunyi di akhir cerita. It means that someone who has told a story that he or she intended to entertain the people. However, the story does not make sense at all to the people; there is no impact to the audience whether the audience can laugh or make the other impacts. Therefore, the meaning based on grammar and lexicon is about the condition of silence or no effect or impact after listening to the story made.

Then, the meaning based on coherence is the context of "Krik Krik." The onomatopoeic of "Krik Krik" is the sound of cricket. In town, there are some noises, so it is rarely the sound of cricket. However, people still can hear the sound of cricket in some small villages; there are no noises.In the place that there is no noise like a big town, it is easy to hear the sound of a cricket.It means in the silence, people can hear the sound of a cricket. Then, in the main label that there is a condition "Selesai cerita, 
penonton kecewa, lampu mati... (hening) Krik

Krik" (After telling a story, the audiences are dissappointed, the light is on... (silence) Krik Krik). In the sentence, it can be seen that someone that wants to entertain the others but since there is no impact, it is like in the situation of silence.

\section{Blend and Acronym Based Jargon}

Blend and Acronymare two different terms althoughsome people think that they are similar. Blend is a blend of two words to become one. Then, it could be usual to pronunce. Blends itself can be the blend of two words or a phrase that one of the components can be blent to the others (McCarthy, 2002: 65).Even, the blends also can change to become a new terms; there are some blends in English, such as "brunch" (breakfast and luch), "smoge" (smoke and rog), Cyborg (Cybernetic Oranism), Horror (Horizontal Terror), etc. In Indonesia, especially in some ethnic languages, there are also some blends, such as "Bulek" (Ibu Cilek), "Mak dang” (Mamak Gadang), etc. In this analysis, there are some contractions that can be some jargons of Aqua. However, Acronym is like an abbreviation (abreviation will be spelled based on the letter). However, Acronym will be pronunced as like it is a word (McCarthy, 2002: 65). There are some examples of Acronym, whether it is in English or in Bahasa Indonesia. The examples are RAM (Random Acess Memory), NATO (North Atlantic Treaty Organisation), AIDS (acquired immune deficiency syndrome) and even sonar (Sound Navigation and Ranging). Then, still in this analysis, there are some jargons created by Aqua based on Blend and Acronym.

\section{Lalu (Salah dan Malu)}

The first acrony that the researcher analyzed is the jargon "lalu." "Lalu" itself derrives from a phrase "Salah dan malu." It is also taken from parts of the words and then they are combined to become one. After that, there will be an assimilation for making the blend can be easily heard and even it will be remembered easily as the word "lalu" (if it is not a blend), will mean "past." That is the reason why it can be easily heard and remembered.

The meaning based on the cohesion is based on grammar. In this case, the main statement contained of the word "Lalu" is "Ketik "sayang" di grup kantor, kamu... Lalu" (Typing a word "babe" in the office chat group, you are "Lalu"). Therefore, in a full text, the sentence consists of two clauses; the first, "Because of typing the word "Babe" has a reduction "because of" as it is as the adverbial 
clause. It means the phrase "Ketik sayang" (typing "babe") is not the main clause of the sentence; the function is just as the adverb of the sentence. Then, the second clause is "you are... lalu." Then, there will be the meaning of "Lalu" in the bottom of label. The meaning is "Salah dan malu" (wrong and embarrassed). Therefore, the meaning based on the cohesion after seeing the clause, it is about cause and effect. The cause is about the mistake in typing the word "sayang" (babe). Actually, it is not about the mistake in the "word" but it is wrong in the situation. In this case, the mistake is the mistake in typing the word in chat group. Therefore, it will make the others see the word. Then, the second clause is "you are... lalu." Then, the whole sentence means the cause of "lalu" (Wrong and embarrassed). It means the action of typing "sayang" (babe) in the wrong group and the event has made the person ashamed. Then, In the other side of label, there is such a "lexical" meaning of lalu. There, the lexical meaning is "[la.lu]: tindakan kurang fokus yang berakibat malu tingkat dewa" (The action of less focus that has an impact of ashamed in the level of god)." If it is related to the main sentence, it means that the action is the impact of less focus. Therefore, the action of wrong typing in the wrong chat group is tthe impact of less focus.

Then, the meaning based on coherence will be related to the context of text made.Based on the text on the main label of Aqua, the meaning of "Sayang" (babe) is dedicated to someone that is closed or loved by a person. It means he or she will call "sayang" (babe) as an adress to someone that he or she loves. Adress itself is the term for calling someone (Wardaugh, 2006; 268). There are several ways for addressing the others. Sometimes, some people will use the polite way to address someone, such as by calling him or her by "Mr", "Miss", "Aunt", etc. In this case, someone here is calling the one he or she loves by calling "sayang" (babe) that is more personal. However, it is not usual if the adress "sayang" (babe) is shown in a chat group and then even it will make the person embarrassed.

\section{a. GEJE}

The second one of the analysis is included into acronym because the person should not spell it and it will follow like two syllables. Then, Geje is an acronym of $\mathrm{G}$ and $\mathrm{J}$ that it derrives from the phrase "Nggak Jelas" (Not clear). However, some people in Indonesia sometimes will pronunce the word "Nggak" just by pronuncing "Gak." Thus, it is 
why it is begun with the letter "G" and not "N." The analysis was begun with cohesion at first. As usual, in the main label, there is a sentence "Minuman dingin kok ditiupin?" (It is a cool water, why should you blow it up?). In Bahasa Indonesia, the sentence consists of two clauses; minuman dingin (It is a cool water) but there is a process of reduction there. Therefore, the full clause is "it's a cool water." It means the water that the person holds is cool or in the condition of cool. It is a unusual statement. However, the second clause is "kok ditiupin?" (why should you blow it up?) means wondering. Therefore, if the clauses are combined to become one, It can be seen clearly the silly thing that a person did has made some people confused. Then, it will be explained by the temporary meaning of GEJE that is on the bottom of the label. The meaning is "Gak Jelas" (Not clear). It means the person did something that makes the other people confused or the person did unusual thing; in this case, the water that he or she holds is not hot but he or se treats it as it is hot (he or she blows it up). Then, the meaning is strengthened in the explanation of the meaning of GEJE (still in the label but it is like in a dictionary; [ge.je] tindakan tidak fokus, elegan dan boros tenaga yang nihil hasil (unfocused action, elegant and overaction that is without any results). Then, the relationship of the statement of blowing the cool water is an unusual. It looks like an elegant action but it is nothing.

Then, the analysis in coherence way is based on the situation and condition in the text. It means that it will be analysed based on the context surrounding the text. The main text says "Minuman dingin kok ditiupin?" (It is a cool water, why should you blow it up?). If it is related to the meaning (still in the label), the person wants to have an elegant looking, However, the others who see it carefully and see that there is no steam surrounding the cup, will think that itis an usual activity and it looks strange.

\section{b. Bingo}

Some people think that the term of "Bingo" derrives from a foreign language. Even, when someone finds the thing that is rally hard to find, he or she will say the word. Actually, it is about card game. When one won the game, he or she will say "bingo." However, "Bingo" in this analysis is not about the game, the term may take such an interest to some people, but it is not about lucky; it is a blend. The meaning of Bingo itself is "Bingung and melongo" (confused and surprised). The meaning based on cohesion will be analysed 
based on the main statement of the bottle "hah.. hah... gimana... gimana" (huh... huh... how... how...). The meaning of "hah" is about someone who is surprised about something. Being surprised here is not being surpised about something special. It is about someone who is confused about something. Then, the cnfusion is getting worse when he or she repeats the word "hah." It means that he or she does not understand at all with the statement he or she heard. Then, there are two question words "bagaimana?" (how?) that it also explains that he or she is couriosed but still confused. That is why the person is in the condition of "Bingo" (Bingung dan Melongo). The meaning of Bingo itself can be seen on the bottom of the main statement and it will be explained near the statement (like the meaning in the dictionary); [bing.o] "bingung sangat amat yang menjatuhkan rahang dan membekukan gerakan" (very confused that affects the mouth and make the move frozen).It means the meaning of bingo is a real confusion that has frozen the activity in progress.

Then, the meaning based on the coherence is about the focus of the person is not so well so that he or she is really hard to understand. If it is analysed based on the main siatuation "hah... hah... bagaimana... bagaimana..." it looks that the person has listened to such an utterance but he or she still does understand the meaning of the sentence or the utterance. Then, based on the repetition in the question word "bagaimana" (how), he or she wants the person that told about something wants to repeat his or her sentence.

\section{Pidgin Based Jargon}

In some languages, the term of Pidgin is so important to form another language and it also can improve the other languages. Pidgin itself is not an original language owned by an area. Then, the people tried to use the language However, sometimes it is really hard for the natives to pronunce the strange words; they tried to pronunce it by their own way or style. Therefore, it is not like the original ones (Wardaugh, 2006: 39). Still discussing about jargonitis, there are some Jargons that are based on the Pidgin. In this case, the English vocabulary. However, it is like the other English it will be fitted to Bahasa Indonesian characteristics.

\section{a. Distrek}

The word "Distrek" is not an Indonesian original word. Actually, it is hard for the researcher to find the meaning at first because it is not usual. However, the researcher find the word "dis" as the first morpheme of the word. 
Morphologically, the morpheme "dis" is not an original morpheme from Indonesia. The morpheme "dis_" is a bound morpheme; it is meaningless without the free morpheme. The meaning of "dis_" is "not" or "no" as examples; disability means not able, disadvantage means no advantage, etc (McCarthy, 2002: 54). Then, the researcher tries to find the meaning of "trek." It is hard to find the meaning of "trek" unless the researcher tries to find based on the sound. The sound of "trek" is almost similar to the sound of "track." Therefore, the full word of "distrek" in English is "distrack." The meaning of distrack is "draw away somebody's attetion from something" (Hornby, 1987: 251). Then, the researcher analysed the meaning of the label of Aqua. There are two related meaning of "Distrek" (Distrack); the first is on the bottom after the main statement. Distrek is "Teralih perhatian" (away from the attention). Then, in the dictionary of Aqua, the meaning is "(dis.trek): fokus pada tujuan utama yang tercampakan oleh keindahan lainnya" ((dis. Trek): focusing on the main goal that is away by the other beauty). In conclusion, the meaning on Oxford's dictionary and the Aqua Dictionary means similar. That is why itis included into Pidgin based Jargon. Then, the main statement will be analysed based on the cohesion, in this case grammar. The main statement says, "Mau kenalan, halte kelewatan, kamu ke_distrek." (Want to introduce yourself to someone but you pass the bus station, you are disracted." It means that someone who meets a boy or a girl and then he wants to know the boy and the girl. In the same situation, the someone passed the bus station as the main goal. That is why he or she is distracked.

Then, the meaning based on coherence is by seeing the main sentence first. It means the boy or the girl actually has a main focus to get the near bus station. However, before getting to the bus station, he or she found a boy or girl that looks attractive. Then, he or she tries to approach the boy or the girl and wants to intriduce him or herself. However, it has made him or her distracked; he forgot to get the bus station.

\section{b. Sekip}

The term of "Sekip" is a term that some people always hear. And actually, it is an English word. The meaning of skip itself is. Then, the term is really famous in some fields, as an example, the word is contained in a computer field such as "skip this step." Therefore, it can be concluded that "skip" 
means that someone passes the scenery that he or she has made.

In this term, the researcher will analyse based on the coherence firstly. Based on the main logo, there is a sentence. The main ssentence says, "Tadi ada di rumah. Kenapa sekarang ada di taman?" (I was at home. However, why can I be in the garden?) The main statement has described about the condition of the person at past. In this case, he or she was at home.However, he or she is in the village wihout realizing the steps why she can be there. It happens because he or she does not have a focus for stepping forward. Then, in the explanation of the next label, there is the meaning of sekip; [se.kip]: "fokus hilang timbul, sehingga tahap tahap kehidupan terlewatkan" ([sekip]: "the fokus is up and down then the phases of life are passed). Then, the meaning of sekip in the explanation is about passing the phase of some phases. Like in the sentence, "I was at home. However, why can I be in the garden?" means that the person has passed one phase or even the phases from home to the garden.

The meaning in coherence is about the meaning in communicative. In this case, the researcher relates the main sentence to the context. The context is about passing one phase of a cycle. However, the person did not realize the skipping phase. It means the person just experience two phases; at home and in the garden without knowing the way of getting to the garden. Sometimes, aperson that has a little focus does not realize the steps of a cycle because he or she is thinking about something.

\section{DISCUSSION}

Therefore, based on the analysis made, the creator of jargon tried to interest some teenagers with some interesting jargons.Then, the creator of Jargon also tries to design the jargon for making it more interesting. As the example, the main statement/ sentence is replaced in the main label. Therefore, it can be seen by some teenagers as the main target or as the market target. It is also written in a big letter so it is read clearly. Generally, the main sentence contains of a statement that will make the teenagers attracted. Sometimes, the main sentence or the statement contains of some funny things. Then, below the main sentence, there will be a hash (\#). The meaning of a hash itself is like a link. Based on webopedia, "producing hash values for accessing data or for security. A has value (or simply hash) also called a message digest, is a number generated from a string of a text... The recipient then 
descrypts both the message and the hash, produces another hash from the received message, and compares the two hashes" (www.webopedia.com>TERM>hashing).

Therefore, the implicit meaning is in the hash made. All the jargonitis must use the hash with the question sentence, "ada Aqua?" (Is there Aqua). Therefore, it is the intention of the creator of the jargon; for making the teenager with the same problem and then they will take the hash (\#). The hash itself will remind them about Aqua. And even, it will remind them about the previous advertisement of Aqua, "we will lose our focus if we are dehydrated."

Thus, there are some relationship of the old advertisement on television that some people has watched to the recent jargonitis. Actually, it is such a little trick from Aqua for making the teenagers interested. It also can be said that the advertisement makes such a link to the audience for the next advertisement. In other words, the advertisement has some sequels.

Then, there is an asterisk after the main sentence that it also refers to something. In this case, it is like the link in the previous discussion. However, the meaning of asterisk there is the short meaning of the jargonitis used. Thus, the reader of the bottle will know the intention and the meaning of the jargon creator.

\section{CONCLUSION}

Based on the results and the analysis made, there is a conclusion that the jargonitis made by the creator of Aqua has thought for the jargon can be effective for the teenagers can use the jargons or even will buy the mineral water in the medium size. The medium size is akso a product offering to the teenagers as the teenagers are active people and they usually buy the medium size. Therefore, it is planned that the roducts should be efffective for teenagers. As the starting point, before the jargonitis made by the creator, the company has released an adertisement describing some people that has lost the focus as the effect of dehydration. Then, there is such a primary jargon, “Ada Aqua?” (Is there Aqua?).

Then, the advertisement continued to the recent advertisement and jargons. The jargons themselves are designed with the main sentence as the opening. It is written in large font so some teenagers can read them. The sentence contains with some interesting topics or even they are funny. It can attract some teenagers that are reading the main sentence. Then, it is followed with the jargon in medium font $i$ 
single word. Then, after the jargon, there will be a hash (\#) with an interrogative sentence “Ada Aqua?" (Is there Aqua?." The jargon and the main sentence try to persuade the teenagers to buy "Aqua" and not the other mineral water. If it is general (losing focus because of dehydration), the suggestion can be "drink some water" but it is "Aqua" as the brand of mineral water. Besides, there is also an asterisk that has a function as a link after the jargon. The link itself has a function for explaining the meaning of the jargon; in a short meaning. Then, the full meaning of jargon with the pronunciation is replaced beside the main sentence. The full meaning is with the pronunciation and even with the syllable how to pronunce the jargon. Then, it is followed with the meaning in a detailed description although the meaning is not so formal; it is in communicative language.The jargons are divided into three kinds; onomatopoeic jargons, Blend and Acronym based Jargon, and Pidgin Based Jargon.

\section{REFERENCES}

Antia, Bassey Edem. 2000. Terminology and Language Planning: An Alternative Framework pf Practice and Discourse. Philadelpia: John Benjamins Publishing Company.

Akcay, Okan. Marketing to Teenagers: The

Influence of Color, Ethnicity and

Gender (International Journal of

Business and Social Science Vol 3

No.22/ Special Issue- November 2012)

Beaugrande, Robert De. 1981. Introduction to

Text Linguistics. UK: Longman House

Baker and Ellece, 1988: 16

Cresswell, John W. 2003. Research Design:

Qualitative, Quantitative and Mixed

Methods Approach. New Delhi: Sage

Publication

Kothari, C.R. 2004. Research Methodology:

Methods and Techniques. New Delhi:

New Age International Limited

Publisher

Krippendorf, Klaus. 2004. Content Analysis

(An Introduction to Its Methodology).

Pennsylvania: University of

Pennsylviana.

Larsen, Fridrik. 2014. Branding as a Bridge for

Connodities towards a Liberalized Market: A 
Study in the Electricity Sector. Journal of

Economics and Management Volume 15, 2014

(University of Economics in Katowice)

Mahdad, Hynd. 2012. Language Change and

Lexical Variationin Youth Language:

Tlemcen Speech Community (Magister

Thesis of University of Tlemcen.

Malmkjær, Kirsten.1995. The Linguistics

Encyclopedia. London and New York:

Routledge.

Martinez, Ignacio M. Palacios. 2011. The

Language of British Teenagers. A

Preliminary Study of its Main

Grammatical Features. (Journal of the

Spanish Association of Anglo-American

Studies. 33.1 (June 2011): 105-126

ISSN 0210-6124) Mahdad, Hynd. 2012.

Language Change and Lexical

Variationin Youth Language: Tlemcen

Speech Community (Magister Thesis of University of Tlemcen.

Malmkjær, Kirsten.1995. The Linguistics

Encyclopedia. London and New York:

Routledge.

Martinez, Ignacio M. Palacios. 2011. The Language of British Teenagers. A Preliminary Study of its Main
Grammatical Features. (Journal of the Spanish Association of AngloAmerican Studies. 33.1 (June 2011): 105-126 ISSN 0210-6124)

McCarthy, Andrew Carstairs. 2002. An Introduction to English Morphology: Words and their Structures. Edinburgh: Edinburgh University Press.

Murphy, M. Lynne and Anu Koskela. 2010.

Key Terms in Semantics. New York:

Continuum

Patoko Ngueviuta and Rashad Yazdanifard. 2014. The Impact of Using Many Jargon Words, while Communicating with the Organization Employees. American Journal of Industrial andBusiness Management, 2014, 4, 567-572 Published Online October 2014 in SciRes. http://www.scirp.org/journal/ajibm and http://dx.doi.org/10.4236/ajibm.2014.4 $\underline{10061}$ 
Queensland Government. 2013. Teenagers and Crisis. Queensland: Mental Health Alcohol and Other Drugs Directorate, Queensland Health

Schlais, Dennis E. Et al. 2011. Introduction to Business (Third Edition). USA: Association Global View.

Sword, Helen. 2012. Stylish Academic Writing. USA: Hardvard University Press.
Wardaugh, Roland. 2006. An Introduction to Sociolinguistics (fifth Edition). USA: Blackwell Publishing.

www.webopedia.com>TERM>hashing accessed on July 2nd, 2017 